\title{
What is The Main Problem in The Conservative Management of Complicated Appendicitis? A Meta- Analysis.
}

\section{Chi Zhang}

Affiliated Hospital of Medical College Qingdao University

\section{Xuemeng Ren}

Affiliated Hospital of Medical College Qingdao University

Peng Gao ( $\sim 445155875 @ q q . c o m$ )

Affiliated Hospital of Medical College Qingdao University https://orcid.org/0000-0003-0769-3754

\section{Research}

Keywords: Appendiceal abscess, Complicated appendicitis, Appendectomy, Conservative management

Posted Date: July 6th, 2020

DOI: https://doi.org/10.21203/rs.3.rs-40033/v1

License: (c) (i) This work is licensed under a Creative Commons Attribution 4.0 International License.

Read Full License 


\section{Abstract}

Background: As one of the classified groups of appendicitis, complicated appendicitis has no standardized treatment methods for adults.

Method: The efficacy of surgical treatment and conservative treatment for complicated appendicitis was evaluated based on the literatures systematically searched on PubMed, Cochrane and Web of Science. A focus was given to important aspects, such as the outcomes of the length of stay, operation time, postoperative complications and unplanned additional interventions.

Result: A total of 14 studies were involved in the meta-analysis, which included 845 patients in the immediate operation group (IO) and 756 patients in the conservative management group (CM). The total hospitalization time for patients with surgical treatment was decreased by 1 day (WMD $=-1.29,95 \% \mathrm{Cl}$ $[-2.42,-0.16], P=0.03<0.05)$ compared to that of patients with conservative treatment. The incidence of unplanned additional interventions in patients who underwent emergency surgery is lower than that of patients with conservative treatment $(\mathrm{OR}=0.18,95 \% \mathrm{Cl}[0.11,0.30], \mathrm{P}<0.00001)$. Compared to patients with conservative treatment, patients who received surgery are more likely to develop complications such as wound infection $(\mathrm{OR}=2.41,95 \% \mathrm{Cl}[1.08,5.38], \mathrm{P}=0.03<0.05)$ and intestinal obstruction $(\mathrm{OR}=4.14,95 \% \mathrm{Cl}$ $[2.21,7.75], \mathrm{P}<0.00001)$. The incidence of abdominal abscess in patients with surgery treatment was lower than that of patients with conservative treatment, but the difference was not statistically significant $(\mathrm{OR}=0.9,95 \% \mathrm{Cl}[0.54,1.47], \mathrm{P}=0.66>0.05)$.

Conclusion: In treating complicated appendicitis, patients who received immediate operation, when compared to patients managed under conservative treatment, have shorter hospitalization time and less unplanned interventions; hence significantly reduce the likelihood of readmission. This can decrease the requirements for follow-up treatments and ultimately lower the consumption of medical resources.

\section{Background}

As the most common form of acute abdomen inflammation that, affec about $7-8 \%$ of adults ${ }^{1}$, appendicitis is categorized into two groups: uncomplicated appendicitis and complicated appendicitis. Accounting for about $3.8-5.0 \%$ of acute appendicitis ${ }^{1}$, complicated appendicitis is often related to the rapid development of acute appendicitis or the improper and untimely treatment ${ }^{2}$. The development of exudates, necroses and perforations in the appendix leads to the accumulation of inflammatory factors in the surrounding tissues of the appendix, which then causes the retina and the nearby small intestine to form an appendiceal wrapping of an inflammatory mass or localized abscess containing pus ${ }^{3}$.

For uncomplicated appendicitis, recent meta-analyses ${ }^{4}$ have reported that antibiotic therapy could represent a feasible treatment option. Although the success rates of complication-free treatment generally are higher than those with surgical treatment, some studies have suggested that non-operative 
management for uncomplicated appendicitis does not statistically increase the perforation rates in adults and in pediatric patients receiving antibiotic treatment ${ }^{5,6}$.

However, there are still contradicting views on the treatment of complicated appendicitis. Some studies have shown that patients with complicated appendicitis receiving immediate operation (IO) have shorter hospitalization time and lower recurrence rates compared with those receiving early conservative treatments, such as anti-infection interventions and interval surgical resections ${ }^{7,8}$. Consistently, recent published meta-analysis studies indicate that postoperative complications in patients with early surgery were significantly higher than those receiving of conservative surgery ${ }^{7,9}$.

However, most studies have not focused on abdominal abscess appendicitis, as well as the short-term recurrence after early treatment. Recent advancements in the development of antibiotics and medical technology have enabled the use of new operation procedures, such as, laparoscopic and percutaneous puncture drainage for treating complicated appendicitis ${ }^{10,11}$. The improved treatment methods for complicated appendicitis have changed the recovery rates and the occurrences of complications in patients ${ }^{12}$. This study aims to compare patients with complicated appendicitis treated by surgical treatment with those receiving conservative treatment through meta-analysis using the data from recent related studies.

\section{Methods}

\section{Literature retrieval}

PubMed, Web of Science and Cochrane Central Register of Controlled Trials were used to retrieve relevant studies from year 2000 to 2020 . The first search time is January 20,2020. And the last search time was February 10, 2020. The search strategy combined text words and MeSH terms related to appendectomy or surgical therapy versus conservative management of complicated appendicitis in adults, which included [abscess or phlegmon] and [laparoscopic or open appendicectomy or appendectomy] and [conservative or on-surgical treatment or management].Related articles available on PubMed were also listed as search results to broaden the research library. After removing duplicating literatures, a summary was made using the literatures obtained.

\section{Research data acquisition}

Target studies were screened through by two researchers (author 1 and 2) independently in accordance to the guidelines outlined in the Cochrane Handbook ${ }^{13}$ as well as using unified literature standards. Relevant effect indexes selected for the study, such as author, year, research purpose and sample size and relevant effect indexes selected for the study were sorted out respectively. Collected data were reviewed and discussed by the study organizer. Controversial materials were either selected or excluded as deemed appropriate by the study organizer.

\section{Research selection and exclusion criteria}


Our analyses only included studies that compare surgical methods (laparoscopic or open) and conservative methods (anti-infection interventions or procedures involving early drainage and selective appendectomy).

Eligible studies with the scores higher than 6 according to NOS ${ }^{14}$ scoring system were defined as highquality studies. The evidence quality in randomized controlled studies was evaluated using the method recommended by Cochrane Handbook ${ }^{13}$.

Selected studies fulfilled the following criteria:

1. Only patients over 12 years old with complicated appendicitis over 12 were selected as the study subjects, considering that there are differences in children's development at different ages ${ }^{15,16}$

2. The outcome indicators included at least the hospitalization time, postoperative complications or the total number of complications;

3. The surgical (laparoscopic or open surgery) and conservative (antibiotics, drainage or no drainage) treatment methods were included as the intervention and control measures;

4. The treatment process and results of the surgical and conservative treatment methods were described in detail;

5. The comparative analyses of other studies or similar studies were conducted by the same authors.

6. Randomized controlled studies or retrospective study were include.

The following studies were excluded in our analyses:

1. Studies with unfulfilled selection criteria;

2. Studies with incomplete important outcome data, and without reporting on the results of the two treatments;

3. Studies that only included patients with uncomplicated appendicitis;

4. Studies with inaccessible required data for meta-analysis through public channels;

5. Studies that failed to accurately deduce the outcome.

\section{Outcomes and definitions}

The immediate operation group (IO) included patients with complicated appendicitis who underwent emergency surgical treatment and/or exploration. The conservative management group (CM) included patients with complicated appendicitis who failed early conservative treatment, those who had emergency surgical treatment or elective surgery after early conservative treatment, and those without undergoing surgery at all. The outcomes used to differentiate the 10 group and the $\mathrm{CM}$ group were as follows $\rrbracket$

1. The length of hospital stay included the duration of the first stay, the average length of stay, the postoperation length of stay and the total length of stay with readmission; 
2. The duration of antibiotics application included the time of intravenous antibiotics during the first hospitalization and the time after the development of recurrent appendicitis and other complications;

3. The overall complications referred to the number of complications caused by complicated appendicitis during the whole treatment period including follow-ups. The wound is closed afterwards to prevent the formation of an abscess caused by infections on the surface or deep layer of the skin. Abdominal abscess and ileus obstruction were identified during the whole treatment process as diagnosed by imaging diagnosis or recognized during emergency surgery or interval appendectomy.

4. The unplanned additional interventions referred to unplanned medical interventions such as repeated surgery, emergency surgery and puncture drainage, etc) for recurrent appendicitis, abdominal abscess and other complications. that occurred during the treatment and follow-up period.

\section{Data analyses and processing}

Statistical analyses were performed using the Revman 5.3 software provided by the Cochrane collaboration and the Stata 15.0. For continuous variables, Weighted Mean Difference (WMD) and Standardized Mean Difference (SMD) were used for analysis to calculate the $95 \%$ confidence interval. For continuous variables that were difficult to calculate, the formulas described from the Cochrane Handbook ${ }^{13}, \mathrm{Hozo}^{17}{ } \mathrm{LuO}^{18}$ and Wan ${ }^{19}$ were used. The odds ratio (OR) was employed to analyze the dichotomous variables in the study. An OR value of $<1$ was considered to be beneficial to the IO group. The $O R$ value was considered to be statistically significant with $P<0.05$. A $c^{2}$ test was used to analyze inter-study heterogeneity. When $R>50 \%$, the study is considered heterogeneous. Whilst a fixed effect model was used for homogeneous study $\otimes \mathrm{P}>0.05, P<50 \% \bigotimes$, a random effect model was used for heterogeneous study $\otimes \mathrm{P}<0.05, R>50 \% \bigotimes$. To analyze the publication bias in heterogeneous studies Stata 15.0 was used, with Egger method set at $P<0.1$. The effects of publication bias on the robustness of our meta-analysis was evaluated by metatrim method 20

\section{Results}

A total of 1801 articles were retrieved and 14 studies were chosen according to the literature selection procedures as illustrated in Figure 1. The studies described 845 patients who were treated surgically (group IO) and 756 patients receiving conservative treatment (group CM). A total of 4 and 10 respective randomized controlled (RCT) ${ }^{21-24}$ and retrospective studies (RS) ${ }^{25-34}$ were included. The information from the literatures that are of major concern is shown in Table 1.

\section{Overall complications}

A total of 8 studies ${ }^{22-24,29-33}$ reported the total number of complications within the duration from the onset of the disease to the follow-up period (Figure 2), and a significant heterogeneity was found among the studies $\left(\mathrm{P}<0.05 ; \mathrm{I}^{2}>50 \%\right)$, Overall, patients in group IO had more overall complications, but the difference was not statistically significant, $(\mathrm{OR}=3.41,95 \% \mathrm{Cl}[0.98,11.86], \mathrm{P}=0.05)$. In the subgroup of a retrospective study, patients in group $\mathrm{CM}$ had lower complications than those with surgery $(\mathrm{OR}=7.14$, 
$95 \% \mathrm{Cl}[1.79,28.54], \mathrm{P}<0.05)$. However, there was a strong heterogeneity between the studies $\left(\mathrm{P}<0.05 ;\left.\right|^{2}>\right.$ $50 \%)$.

\section{Overall duration of hospitalization}

A total of 13 studies ${ }^{21-27,29-34}$ reported the overall duration of hospitalization (Figure 3. A). Heterogeneity was found to exist in these studies $(P<0.05 ; R>50 \%)$ with no obvious publication bias as shown by Egger test $(P=0.951>0.1)$. The effective $S M D$ values in the random effect model did not change significantly before $\left(\mathrm{SMD}_{1}=-0.580,95 \% \mathrm{Cl}[-0.696,-0.465]\right)$ and after $\left(\mathrm{SMD}_{2}=-0.735,95 \% \mathrm{Cl}[-1.338,-0.132]\right)$ evaluation by metatrim method, and the results were found to be robust. Aggregate analysis showed that the length of stay for patients treated with surgery was about 1 day less than that of those receiving conservative treatment, and the difference was statistically significant (WMD $=-1.29,95 \% \mathrm{Cl}[-2.42,-0.16]$, $P=0.03<0.05)$.

\section{Abdominal abscess}

There were 11 studies $21,23,24,27-33$ that reported the occurrence of abdominal abscess (Figure 3. B). In one study, patients with diffuse peritonitis that were classified by Brown ${ }^{26}$ as abdominal abscess, which did not meet the requirements of this study and therefore not included in the meta-analysis. The remaining 10 studies showed homogeneity $(P>0.05 ; R<50 \%)$, but the difference was not statistically significant $(\mathrm{OR}=0.9,95 \% \mathrm{Cl}[0.54,1.47], \mathrm{P}=0.66>0.05)$.

\section{Unplanned additional intervention}

A total of 10 studies 22,23,25-28,30,31,33,34 reported the occurrences of unplanned interventions during treatment in each group (Figure 3. C), which included conservative treatment failure, recurrent appendicitis and postoperative intestinal fistula. There was no significant heterogeneity among the studies $(P>0.05 ; R<50 \%)$. Our analysis showed that the incidence of unplanned additional interventions in the 10 group was significantly lower than that of the $\mathrm{CM}$ group, and the difference was statistically significant $(\mathrm{OR}=0.18,95 \% \mathrm{Cl}[0.11,0.30], \mathrm{P}<0.00001)$.

\section{Wound infections}

A total of 12 studies reported the incision infection (Figure 4. D), among which there were 3 RCTS 21,22,24 and 9 retrospective studies ${ }^{25-33}$. The summarized results showed that patients in the $\mathrm{CM}$ group had a lower incidence of incision infection than those in the IO group $(\mathrm{OR}=2.733,95 \% \mathrm{Cl}[1.243,6.012]$, $P=0.01<0.05)$. The studies were found to be heterogeneous $(P<0.05), R>50 \%)$. With wound infection as indicators, analysis using Egger showed that publications were biased $(P=0.001<0.1)$. Consistently, analysis using metatrim method also indicated publication bias $(P=0.464>0.05)$. In addition, the metaanalysis results of wound infection were found to be irreproducible. Further analysis showed that in four of the studies ${ }^{26-28,31}$ with 386 participants, percutaneous drainage was performed as required in the CM 
group. Compared with that of the IO group, the difference was statistically significant $(\mathrm{OR}=2.41,95 \% \mathrm{Cl}$ $[1.08,5.38], P=0.03<0.05)$. No heterogeneity was found among the studies $(P>0.05 ; R=0 \%$; Figure 4 . $E)$.

\section{Post-operation stay}

Four studies $27,29,33,34$ that reported the length of postoperative stay (Figure 5. F) were found with interstudy heterogeneity $(P<0.05 ; R>50 \%)$. There was no significant publication bias $(P=0.859>0.1)$ for the postoperative hospitalization time as indicated by analysis using Eager method. Meta-analysis results showed that the postoperative hospitalization time of patients undergoing surgical treatment was longer than that of patients after interval operation, and the difference was statistically significant $(S M D=0.66$, $95 \% \mathrm{Cl}[0.42,0.91], \mathrm{P}<0.00001)$.

\section{Intestinal obstruction}

Six studies $26,27,30-33$ that reported the presence of intestinal obstruction in the 10 group and the CM group (Figure 5. G), showed homogeneity $(P>0.05 ; R=0 \%)$. The analysis showed that the incidence of intestinal obstruction was higher in surgical treatment than that in conservative treatment $(\mathrm{OR}=4.14,95 \% \mathrm{Cl}[2.21$, 7.75], $\mathrm{P}<0.00001)$.

\section{Post-operative complications}

There were 5 studies $22,28,30,32,33$ included in the analysis of postoperative complications (Figure 5. H),. No significant heterogeneity was found among the studies $(P>0.05, R<50 \%)$. The analysis showed that, compared with conservative treatment, postoperative complications were more common in immediate appendectomy $(\mathrm{OR}=15.83,95 \% \mathrm{Cl}[8.31,30.14], \mathrm{P}=0.1>0.05)$.

\section{Other outcomes}

The analysis results of operate time $28,29,33,34$, intestinal fistula $22,26,27,29,30$, sepsis $^{24,26,27,32}$, necrosis ${ }^{24,26}$, DVT $^{31,32}$, pulmonary infection ${ }^{31,32}$ are shown in Table 2.

\section{Discussion}

In this study, we demonstrated that the total duration of hospitalization for patients with surgical treatment was decreased by about 1 day compared with those receiving conservative treatment. Despite the high heterogeneity, the event outcome was not reversed according to after the estimation by metatrim method, indicating that our meta-analysis was robust. In agreement with a previous study ${ }^{23}$, the incidence of unplanned additional interventions in patients undergoing emergency surgery was lower than that of conservative treatment, showing that patients undergoing conservative treatment were more likely to have emergency surgery or readmission due to failure of conservative treatment, recurrent appendicitis, abdominal abscess and potential malignancy. 
However, patients undergoing 10 are more prone to complications, such as wound infections and intestinal obstructions than those receiving CM. This may be related to the non-sterile abdominal environment during emergency surgery, while the conservative treatment group has a selective drain of the abdominal abscess to improve the environment. Meta-analysis of abdominal abscess showed that the incidence of abdominal abscess is not statistically significant different between the two groups. However, due to the lack of rigorous RCT studies, and the variety of patients, it is difficult to accurately determine the merits of surgery compared to those of percutaneous drainage for abdominal abscess.

Based on published guidelines, there is currently no standard treatment for complicated appendicitis with localized perforation, abscess or mass formation ${ }^{35}$. In some hospitals, 10 for complicated appendicitis remains the preferred treatment method for many surgeons. In recent years, the efficacies of conservative treatment for complicated appendicitis and whether or not to perform interval surgeries have been questioned ${ }^{27,36}$. Some patients with complicated appendicitis underwent surgical treatment to remove tumors found in the ileocecal part after successful conservative treatment. A small percentage of patients with conservative treatment ended up having worse symptoms that lead to more surgical treatments. In addition, the patients were required to continue the treatment. The patients with failed conservative management were eventually excluded from the analysis, which may lead our data analysis to be more inclined to non-surgical treatment.

As the follow-ups after discharge became more detailed, there were some obvious issues caused by conservative treatment, such as recurrent appendicitis, missed potential malignancies and unconsolidated appendicitis progressing to appendiceal mass. In the published similar meta-analysis, although similar conclusions were obtained, there was a high degree of heterogeneity among the studies. This study guarantees the robustness of the research results through matetrim. And it clearly highlighted that conservative treatment resulted in more additional operations for patients through the summary of studies in the last 20 years. At the same time, through statistical reasoning, this meta-analysis demonstrated that surgical patients have a shorter duration of hospitalization.

Longer hospitalization, more antibiotic applications and more unplanned treatments often result in higher costs for patients. In addition, recurrent appendicitis and potential tumors require multiple imaging and laboratory tests. This not only increases the burden of patients, but also consumes a large amount of medical resources. Repeated admissions also tend to increase the cost of inpatient management. While the complications of emergency surgical treatment for complicated appendicitis often occur during the first admission, some minor complications such as wound infection can be treated at lower-level medical institutions. Hence surgical treatment is obviously better than conservative treatment for complicated appendicitis..

The results of this study highlighted some of the limiting aspects. For instance, most studies did not report a clear application duration of intravenous antibiotics, therefore unable to be included in our evaluation. There are also differences in the organ development due to young age in children, which widens the biggish differences of the organ in preventing infection. This study only focused on patients 
over the age of 12. Although the heterogeneity of analysis results was low in some studies, it should be noted that the overall clinical status of patients in each group varied considerably. Even if there was statistical equivalence in some key results between the two groups, the utilization of medical resources and perioperative care remained inconsistent. Unfortunately, although several studies have demonstrated the effectiveness of laparoscopic surgery in emergency surgical treatment of complicated appendicitis ${ }^{37,38}$, compared to conservative treatment, rigorous RCTS for laparoscopic treatment was lacking. Although few RCTs were included in this study, the outcome and descriptions of the process in some RCT studies were not clear. Whilst a number of studies have demonstrated the effectiveness of laparoscopy appendectomy ${ }^{23}$, in treating the complications, some retrospective studies utilized open appendectomy as the main treatment method. Compared to laparoscopic and conservative management, data from RCT experiments were insufficient in our analyses

\section{Conclusions}

Patients receiving immediate operation have a shorter hospitalization duration and less unplanned interventions than those with conservative management. This showed that immediate operation can significantly decrease the likelihood of readmission for patients with complicated appendicitis, therefore lighten the burden of follow-ups and medical resource consumption. At the same time, it is consistent with the recently published WSES appendicitis diagnosis and treatment guidelines ${ }^{39}$. Through further research on heterogeneity, this study ensures the robustness of the conclusion. Future randomized controlled trials with more laparoscopic surgery instead of conservative treatment will better clarify the effectiveness of IO, and ultimately contribute to the establishment of appropriate methods for treatingcomplicated appendicitis.

\section{List Of Abbreviations}

IO: immediately operation;

CM: conservative management;

IAA: interval appendectomy;

RS: retrospective study;

RCT: randomized controlled trial

WMD: Weighted Mean Difference

SMD: Standardized Mean Difference

\section{Declarations}


This research did not receive any specific grant from funding agencies in the public, commercial, or notfor-profit sectors

\section{Ethics approval and consent to participate}

Not applicable

\section{Consent for publication}

Not applicable

\section{Availability of data and materials}

All data in this article are derived from published articles, and the data generated or analysed during this study are included in this article.

\section{Competing interests}

The authors declare that they have no competing interests.

\section{Funding}

All financial support in this study came from corresponding author sponsorship

\section{Authors' contributions}

Each author is responsible for the design of the study, the analysis of the data and the drafting and revision of the article, and ensure that questions related to the accuracy or integrity of any part of the work

The Corresponding authors Peng Gao ensure that all listed authors have approved the manuscript before submission, including the names and order of authors, make it certain that no author on earlier versions have been removed or new authors added, and all data comply with the transparency and reproducibility standards of both the field and journal.

\section{Acknowledgements}

Thanks to Lelong Qu and Bailing Zhang for their help on English writing. And Zhenlu Li give the help of data-gathering approach.

\section{Authors' information}

The author Chi Zhang is a graduate student of the affiliated hospital of Qingdao university, who is engaged in emergency surgery. He has come into contact with many patients with acute appendicitis in his work, and has great interest in the treatment of acute appendicitis. 


\section{References}

1. Tannoury J. Treatment options of inflammatory appendiceal masses in adults. World J Gastroenterol. 2013;19:3942. doi:10.3748/wjg.v19.i25.3942.

2. Hansson LE, Laurell H, Gunnarsson U. Impact of time in the development of acute appendicitis. Dig Surg. 2008;25:394-9. doi:10.1159/000180451.

3. Ahmed I, Deakin D, Parsons SL. Appendix mass: do we know how to treat it? Ann R Coll Surg Engl. 2005;87:191-5. doi:10.1308/1478708051649.

4. Podda M, et al. Antibiotic Treatment and Appendectomy for Uncomplicated Acute Appendicitis in Adults and Children: A Systematic Review and Meta-analysis. Ann Surg. 2019;270:1028-40. doi:10.1097/sla.0000000000003225.

5. Sippola S, et al. Quality of Life and Patient Satisfaction at 7-Year Follow-up of Antibiotic Therapy vs Appendectomy for Uncomplicated Acute Appendicitis: A Secondary Analysis of a Randomized Clinical Trial. JAMA Surg. 2020. doi:10.1001/jamasurg.2019.6028.

6. Prechal D, Post S, Pechlivanidou I, Ronellenfitsch U. Feasibility, acceptance, safety, and effectiveness of antibiotic therapy as alternative treatment approach to appendectomy in uncomplicated acute appendicitis. Int J Colorectal Dis. 2019;34:1839-47. doi:10.1007/s00384-019-03392-1.

7. Darwazeh G, Cunningham SC, Kowdley GC. A Systematic Review of Perforated Appendicitis and Phlegmon: Interval Appendectomy or Wait-and-See? Am Surg. 2016;82:11-5.

8. Dong Y, Tan S, Fang Y, Yu W, Li N. [Meta-analysis of laparoscopic surgery versus conservative treatment for appendiceal abscess]. Zhonghua Wei Chang Wai Ke Za Zhi. 2018;21:1433-8.

9. Gavriilidis P, de'Angelis N, Katsanos K, Di Saverio S. Acute Appendicectomy or Conservative Treatment for Complicated Appendicitis (Phlegmon or Abscess)? A Systematic Review by Updated Traditional and Cumulative Meta-Analysis. J Clin Med Res. 2019;11:56-64. doi:10.14740/jocmr3672.

10. Jeffrey RB Jr, Federle MP, Tolentino CS. Periappendiceal inflammatory masses: CT-directed management and clinical outcome in 70 patients. Radiology. 1988;167:13-6. doi:10.1148/radiology.167.1.3347712.

11. Bagi P, Dueholm S, Karstrup S. Percutaneous drainage of appendiceal abscess. An alternative to conventional treatment. Dis Colon Rectum. 1987;30:532-5. doi:10.1007/bf02554784.

12. Olsen J, Skovdal J, Qvist N, Bisgaard T. Treatment of appendiceal mass-a qualitative systematic review. Dan Med J. 2014;61:A4881.

13. Higgins JPT, Chandler TJ, Cumpston J, Li M, Page T, Welch MJ VA, editors. Cochrane Handbook for Systematic Reviews of Interventions version 6.0 (updated July 2019). Cochrane, 2019. Available from .

14. Stang A. Critical evaluation of the Newcastle-Ottawa scale for the assessment of the quality of nonrandomized studies in meta-analyses. Eur J Epidemiol. 2010;25:603-5. doi:10.1007/s10654010-9491-z. 
15. Kirby CP, Sparnon AL. Active observation of children with possible appendicitis does not increase morbidity. ANZ J Surg. 2001;71:412-3. doi:10.1046/j.1440-1622.2001.02148.x.

16. Xinwei L. Observation of the clinical and pathological character of child acute appendicitis. CHINA MEDICAL HERALD. 2012;9:174-5.

17. Hozo SP, Djulbegovic B, Hozo I. Estimating the mean and variance from the median, range, and the size of a sample. BMC medical research methodology 5, doi:10.1186/1471-2288-5-13 (2005).

18. Luo $D$, Wan $X$, Liu J, Tong T. Optimally estimating the sample mean from the sample size, median, mid-range, and/or mid-quartile range. Stat Methods Med Res. 2018;27:1785-805. doi:10.1177/0962280216669183.

19. Wan X, Wang W, Liu J, Tong T. Estimating the sample mean and standard deviation from the sample size, median, range and/or interquartile range. BMC medical research methodology. 2014;14:135. doi:10.1186/1471-2288-14-135.

20. Duval S, Tweedie R. Trim and fill: A simple funnel-plot-based method of testing and adjusting for publication bias in meta-analysis. Biometrics. 2000;56:455-63. doi:10.1111/j.0006341x.2000.00455.x.

21. Khan SA, Ali M, Seerat MI. Efficacy of Early Exploration in Appendicular Mass. Pak J Med Health Sci. 2016;10:781-3.

22. Kumar S, Jain S. Treatment of appendiceal mass: prospective, randomized clinical trial. Indian journal of gastroenterology: official journal of the Indian Society of Gastroenterology. 2004;23:1657.

23. Mentula P, Sammalkorpi H, Leppaniemi A. Laparoscopic Surgery or Conservative Treatment for Appendiceal Abscess in Adults? A Randomized Controlled Trial. Ann Surg. 2015;262:237-42. doi:10.1097/sla.0000000000001200.

24. Pathan MF, et al COMPARATIVE STUDY OF IMMEDIATE SURGICAL INTERVENTION VERSUS CONSERVATIVE TREATMENT IN APPENDICULAR LUMP. Indo Am J Pharm Sci. 2018;5:606-10. doi:10.5281/zenodo.1165099.

10.4321/s1130-01082010001100005

25. Aranda-Narvaez JM, et al. Conservative approach versus urgent appendectomy in surgical management of acute appendicitis with abscess or phlegmon. Revista espanola de enfermedades digestivas: organo oficial de la Sociedad Espanola de Patologia Digestiva 102, 648-652, doi:10.4321/s1130-01082010001100005 (2010).

26. Brown CV, Abrishami M, Muller M, Velmahos GC. Appendiceal abscess: immediate operation or percutaneous drainage? Am Surg. 2003;69:829-32.

27. Deelder JD, Richir MC, Schoorl T, Schreurs WH. How to treat an appendiceal inflammatory mass: operatively or nonoperatively? J Gastrointest Surg. 2014;18:641-5. doi:10.1007/s11605-014-2460-1.

28. Demetrashvili Z, et al. Comparison of treatment methods of appendiceal mass and abscess: $A$ prospective Cohort Study. Ann Med Surg (Lond). 2019;48:48-52. doi:10.1016/j.amsu.2019.10.016. 
29. Liu ZF, Yu JC, Hsieh HF, Lin CH. Perforated appendicitis: urgency or interval surgery? Zentralbl Chir. 2007;132:539-41. doi:10.1055/s-2007-981369.

30. Motie MR, et al. Is Interval Appendectomy Necessary for Appendicular Phlegmon? A Prospective Study. Indian J Surg. 2018;80:494-9. doi:10.1007/s12262-017-1644-9.

31. Oliak D, et al. Initial nonoperative management for periappendiceal abscess. Dis Colon Rectum. 2001;44:936-41. doi:10.1007/bf02235479.

32. Shekarriz S, et al. Comparison of conservative versus surgical therapy for acute appendicitis with abscess in five German hospitals. Int J Colorectal Dis. 2019;34:649-55. doi:10.1007/s00384-01903238-w.

33. Watanabe R, et al. Superior outcomes (but at higher costs) of non-operative management with interval appendectomy over immediate surgery in appendicitis with abscess: Results from a large adult population cohort. Asian J Endosc Surg. 2019. doi:10.1111/ases.12726.

34. Young KA, et al. Outcomes of complicated appendicitis: Is conservative management as smooth as it seems? Am J Surg. 2018;215:586-92. doi:10.1016/j.amjsurg.2017.10.032.

35. Di Saverio S, et al. WSES Jerusalem guidelines for diagnosis and treatment of acute appendicitis. World J Emerg Surg. 2016;11:34. doi:10.1186/s13017-016-0090-5.

36. S T, et al. Operative versus non-operative management in the care of patients with complicated appendicitis. (2017).

37. Thomson J-E, et al. Laparoscopic versus open surgery for complicated appendicitis: a randomized controlled trial to prove safety. Surg Endosc. 2015;29:2027-32. doi:10.1007/s00464-014-3906-y.

38. Dimitriou I, Reckmann B, Nephuth O, Betzler M. Single institution's experience in laparoscopic appendectomy as a suitable therapy for complicated appendicitis. Langenbecks Arch Surg. 2013;398:147-52. doi:10.1007/s00423-012-1035-4

10.1186/s13017-020-00306-3

39. Di Saverio S. P. M. e. a. Diagnosis and treatment of acute appendicitis: 2020 update of the WSES Jerusalem guidelines. World J Emerg Surg 2020 Apr 15;15(1):27., doi:doi: 10.1186/s13017-02000306-3 (2020).

\section{Tables}




\section{Tables 1. Characteristics of the Included Studies}

\begin{tabular}{|c|c|c|c|c|c|c|c|c|c|}
\hline \multirow[t]{2}{*}{ Author,year } & \multirow[t]{2}{*}{$\begin{array}{l}\text { Study } \\
\text { type }\end{array}$} & \multicolumn{3}{|c|}{ Case } & \multicolumn{2}{|c|}{$\begin{array}{l}\text { Age (mean } \pm \\
\text { SD) }\end{array}$} & \multirow[t]{2}{*}{$\begin{array}{l}\text { Inclusion } \\
\text { criteria }^{a}\end{array}$} & \multirow[t]{2}{*}{$\begin{array}{l}\text { Matching } \\
\text { criteria }^{b}\end{array}$} & \multirow[t]{2}{*}{ NOS } \\
\hline & & 10 & $\mathrm{CM}$ & IAA & 10 & $\mathrm{CM}$ & & & \\
\hline $\begin{array}{l}\text { Aranda- } \\
\text { Narváez, } \\
2010^{25}\end{array}$ & RS & 15 & 15 & 15 & $\begin{array}{l}35.8 \\
\pm 12\end{array}$ & $\begin{array}{l}35.4 \\
\pm 12\end{array}$ & $1,2,3,5$ & $\begin{array}{l}1,2,6,10 \\
11\end{array}$ & 8 \\
\hline brown, $2003^{26}$ & RS & 36 & 68 & 25 & $\begin{array}{l}30.6 \\
\pm 12.3\end{array}$ & $\begin{array}{l}34.8 \\
\pm 13.5\end{array}$ & $1,2,3,6$ & $\begin{array}{l}1,2,8,10 \\
11,12\end{array}$ & 7 \\
\hline $\begin{array}{l}\text { Deelder, } \\
2014^{27}\end{array}$ & RS & 34 & 85 & $\mathrm{~nm}$ & $\begin{array}{l}41.2 \\
\pm 23.1\end{array}$ & $\begin{array}{l}45.0 \\
\pm 22.1\end{array}$ & $1,2,3,6$ & $\begin{array}{l}12,4,6,7 \\
8,9,10,11 \\
12\end{array}$ & 7 \\
\hline $\begin{array}{l}\text { Demetrashvili, } \\
2019^{28}\end{array}$ & RS & 27 & 47 & 24 & $\begin{array}{l}32.5 \\
\pm 11.7\end{array}$ & $\begin{array}{l}35.2 \\
\pm 12.4\end{array}$ & $\begin{array}{l}1,2,3,5, \\
6\end{array}$ & $\begin{array}{l}1,2,4,5,6 \\
7,8,10,11 \\
12\end{array}$ & 7 \\
\hline khan $S, 2016^{21}$ & RCT & 150 & 150 & 150 & $\begin{array}{l}26.08 \\
\pm 10.6\end{array}$ & $\begin{array}{l}25.89 \\
\pm 9.43\end{array}$ & $1,2,5$ & $1,2,10,11$ & 5 \\
\hline kumar, $2004^{22}$ & $\mathrm{RCT}$ & 20 & 20 & 20 & $\begin{array}{l}31.6 \\
\pm 14.6\end{array}$ & $\begin{array}{l}26.0 \\
\pm 12.4\end{array}$ & $1,2,3,6$ & $\begin{array}{l}1,2,5,10 \\
11\end{array}$ & 6 \\
\hline liu, $2007^{29}$ & RS & 104 & 17 & 17 & $\begin{array}{l}37 \pm \\
10.3\end{array}$ & $\begin{array}{l}41 \pm \\
11.2\end{array}$ & $\begin{array}{l}1,2,3,4 \\
5\end{array}$ & $\begin{array}{l}1,2,5,3,8 \\
10,11,12\end{array}$ & 7 \\
\hline $\begin{array}{l}\text { Mentula, } \\
2015^{23}\end{array}$ & $\mathrm{RCT}$ & 30 & 30 & $\mathrm{~nm}$ & $\begin{array}{l}46.1 \\
\pm 27.1\end{array}$ & $\begin{array}{l}46.5 \\
\pm 27.2\end{array}$ & $1,2,6$ & $\begin{array}{l}1,2,3,4,8 \\
9,10,11\end{array}$ & 7 \\
\hline Motie, $2016^{30}$ & RS & 24 & 49 & 25 & $\begin{array}{l}36.0 \\
\pm 15.5\end{array}$ & $\begin{array}{l}43.2 \\
\pm 19.3\end{array}$ & $1,2,3,6$ & $\begin{array}{l}1,2,8,10 \\
11,12\end{array}$ & 6 \\
\hline Oliak, $2001^{31}$ & RS & 67 & 88 & 52 & $\begin{array}{l}31 \pm \\
10\end{array}$ & $\begin{array}{l}35 \pm \\
15\end{array}$ & $1,2,5,6$ & $\begin{array}{l}\text { 1, 2, 4, 8, } \\
7,10,11,12\end{array}$ & 8 \\
\hline $\begin{array}{l}\text { Pathan, } \\
2018^{24}\end{array}$ & RCT & 50 & 50 & 50 & $21.5 \pm 11$ & & $1,2,3,5$ & $\begin{array}{l}1,2,3,8,10 \\
11,12\end{array}$ & 5 \\
\hline $\begin{array}{l}\text { Shekarriz, } \\
2019^{32}\end{array}$ & RS & 195 & 53 & 41 & $\begin{array}{l}53.55 \\
\pm 21.8\end{array}$ & $\begin{array}{l}56.02 \\
\pm \\
19.65\end{array}$ & $1,2,6$ & $\begin{array}{l}1,2,3,6,8 \\
9,10,11\end{array}$ & 8 \\
\hline $\begin{array}{l}\text { Watanabe, } \\
2019^{33}\end{array}$ & RS & 33 & 49 & 49 & $\begin{array}{l}43.8 \\
\pm \\
19.25\end{array}$ & $\begin{array}{l}39 \pm \\
14.75\end{array}$ & $1,2,5,6$ & $\begin{array}{l}1,2,8,9,10 \\
11\end{array}$ & 7 \\
\hline Young, $2018^{34}$ & RS & 60 & 35 & 14 & $\begin{array}{l}51 \pm \\
19.6\end{array}$ & $\begin{array}{l}50.9 \\
\pm 19.4\end{array}$ & $\begin{array}{l}1,2,4,5 \\
6\end{array}$ & $\begin{array}{l}1,2,3,4,5 \\
10,11\end{array}$ & 8 \\
\hline
\end{tabular}




\section{Tables 1. Characteristics of the Included Studies}

a: Inclusion criteria: 1 . male\& female; 2 . adult patients; 3 . clinical symptoms; 4 . perforated appendix; 5. appendiceal mass; 6 . appendiceal abscess;

b: Matching criteria:1. gender; 2 . age; 3 . BMl; 4 . duration of symptoms; 5 . operate time; 6 . ASA; 7. heart rate; 8 .white cell count; 9 . CRP; 10 . complication; 11 . hospital stay; 12 .temperature.

IO: immediate operation; CM: conservative management; IAA: interval appendectomy; RS:

retrospective study; RCT: randomized controlled trial; NOS: Newcastle-Ottawa scale;Nm: not

mentioned 


\section{Tables 2. Outcomes of Interest}

\begin{tabular}{|c|c|c|c|c|c|}
\hline \multirow[t]{2}{*}{ Outcomes of Interest (study number) } & \multirow{2}{*}{$\begin{array}{l}\text { Number } \\
\text { of }\end{array}$} & \multicolumn{2}{|c|}{$\begin{array}{l}\text { Number of } \\
\text { patients }\end{array}$} & \multirow[t]{2}{*}{$\begin{array}{l}\text { Statistical method, } 95 \% \\
\mathrm{Cl}, \mathrm{P} \text { value }\end{array}$} & \multirow[t]{2}{*}{$\mathrm{I}^{2}(\%)$} \\
\hline & & 10 & $\mathrm{CM}$ & & \\
\hline $\begin{array}{l}\text { overall duration of hospitalization } \\
{[20-26,28-33]}\end{array}$ & 13 & 817 & 709 & $\begin{array}{l}\text { WMD }=-1.29,95 \% \mathrm{Cl}[-2.42 \\
-0.16], P=0.03<0.05\end{array}$ & 93 \\
\hline Post-operation stay $[26,28,32,33]$ & 4 & 224 & 125 & $\begin{array}{l}\mathrm{SMD}=0.66,95 \% \mathrm{Cl}[0.42 \\
0.91], \mathrm{P}<0.00001\end{array}$ & 55 \\
\hline Operate time $[27,28,32,33]$ & 4 & 224 & 104 & $\begin{array}{l}\mathrm{SMD}=0.26,95 \% \mathrm{Cl}[-0.13 \\
0.64], \mathrm{P}<0.00001\end{array}$ & 54 \\
\hline Overall complications [22-24, 29-33] & 8 & 171 & 105 & $\begin{array}{l}\mathrm{OR}=3.41,95 \% \mathrm{Cl}[0.98 \\
11.86], \mathrm{P}=0.05\end{array}$ & 86 \\
\hline $\begin{array}{l}\text { Post-operative complications [21, 27, } \\
29,31,32]\end{array}$ & 5 & 522 & 356 & $\begin{array}{l}\mathrm{OR}=15.83,95 \% \mathrm{Cl}[8.31 \\
30.14], \mathrm{P}=0.1>0.05\end{array}$ & 34 \\
\hline \multicolumn{6}{|l|}{ Wound infections } \\
\hline wound infections $[20,21,23,24-32]$ & 12 & 754 & 625 & $\begin{array}{l}\mathrm{OR}=2.733,95 \% \mathrm{Cl}[1.243 \\
6.012], \mathrm{P}=0.01<0.05\end{array}$ & 57 \\
\hline $\begin{array}{l}\text { wound infections with percutaneous } \\
\text { drainage }[25-27,30]\end{array}$ & 4 & 164 & 222 & $\begin{array}{l}\mathrm{OR}=2.41,95 \% \mathrm{Cl}[1.08 \\
5.38], P=0.03<0.05\end{array}$ & 0 \\
\hline $\begin{array}{l}\text { Abdominal abscess }[20,22,23,26- \\
32]\end{array}$ & 10 & 713 & 618 & $\begin{array}{l}\mathrm{OR}=0.9,95 \% \mathrm{Cl}[0.54 \\
1.47], \mathrm{P}=0.66>0.05\end{array}$ & 38 \\
\hline Bowel obstruction $[25,26,29-32]$ & 6 & 388 & 392 & $\begin{array}{l}\mathrm{OR}=4.14,95 \% \mathrm{Cl}[2.21 \\
7.75], \mathrm{P}<0.00001\end{array}$ & 0 \\
\hline $\begin{array}{l}\text { Unplanned additional interventions } \\
{[21,22,24-27,29,30,32,33]}\end{array}$ & 10 & 345 & 501 & $\begin{array}{l}\mathrm{OR}=0.18,95 \% \mathrm{Cl}[0.11 \\
0.30], \mathrm{P}<0.00001\end{array}$ & 22 \\
\hline
\end{tabular}

Other complications

Operate time [27, 28, 32, 33]
Overall complications [22-24,
Post-operative complications [ 21
$29,31,32]$

\begin{tabular}{|c|c|c|c|c|c|}
\hline Intestinal fistula $[21,25,26,28,29]$ & 4 & 217 & 239 & $\begin{array}{l}\mathrm{OR}=2.80,95 \% \mathrm{Cl}[0.75 \\
10.56], \mathrm{P}=0.13>0.05\end{array}$ & 0 \\
\hline Sepsis $[23,25,26,31]$ & 4 & 315 & 256 & $\begin{array}{l}\mathrm{OR}=0.95,95 \% \mathrm{Cl}[0.41 \\
2.19], \mathrm{P}=0.9>0.05\end{array}$ & 21 \\
\hline Necrosis $[23,25]$ & 2 & 86 & 117 & $\begin{array}{l}\mathrm{OR}=0.15,95 \% \mathrm{Cl}[0.05 \\
0.51], \mathrm{P}=0.002<0.05\end{array}$ & 0 \\
\hline Thromboembolic $[30,31]$ & 2 & 262 & 141 & $\begin{array}{l}\mathrm{OR}=1.88,95 \% \mathrm{Cl}[0.26 \\
13.57], \mathrm{P}=0.53>0.05\end{array}$ & 0 \\
\hline Pulmonary $[30,31]$ & 2 & 262 & 141 & $\begin{array}{l}\mathrm{OR}=9.26,95 \% \mathrm{Cl}[1.68 \\
51.19], \mathrm{P}=0.01<0.05\end{array}$ & 0 \\
\hline
\end{tabular}


Figures

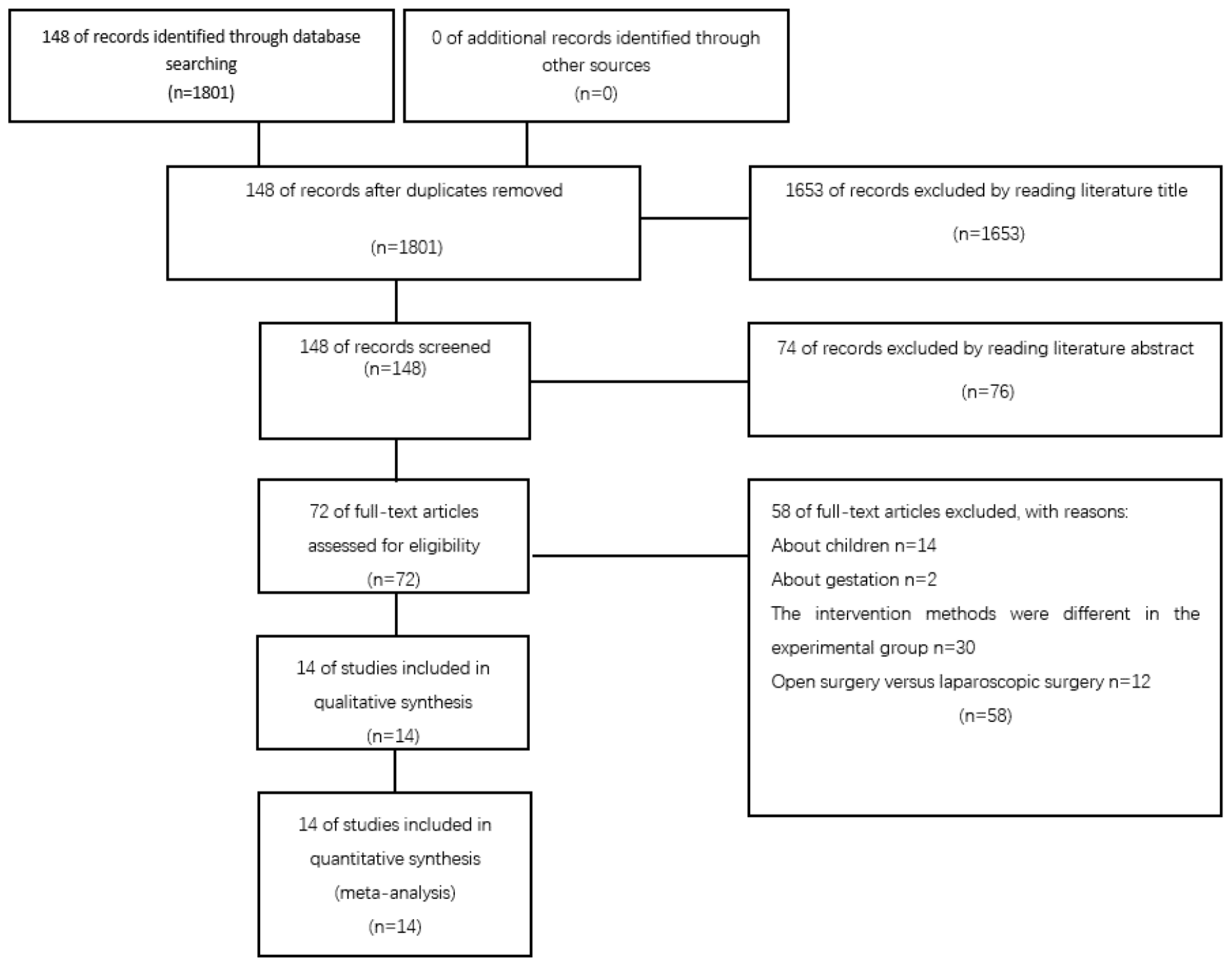

\section{Figure 1}

Study flow diagram. 


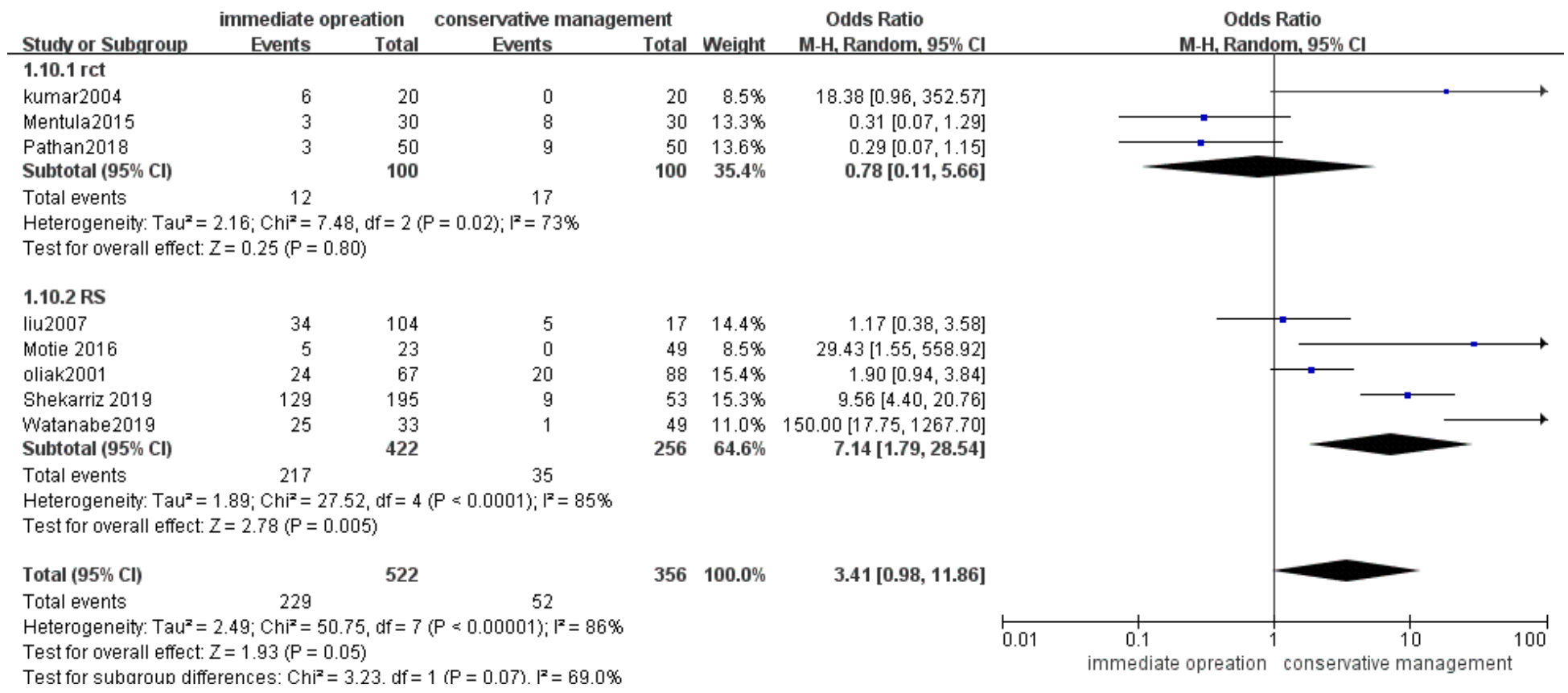

Figure 2

Overall complications 


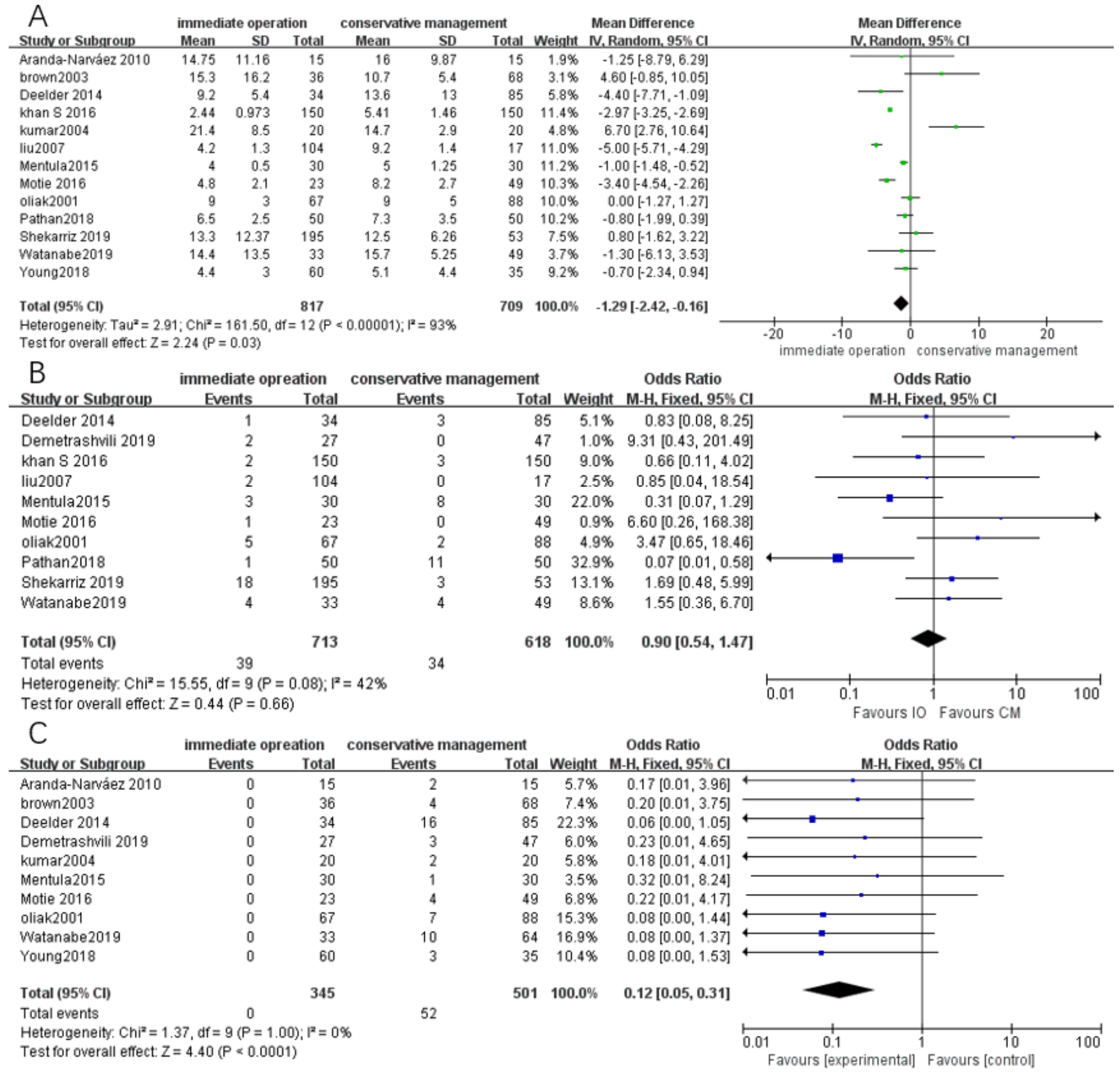

Figure 3

Overall duration of hospitalization. B. Abdominal abscess. C. Unplanned additional interventions 


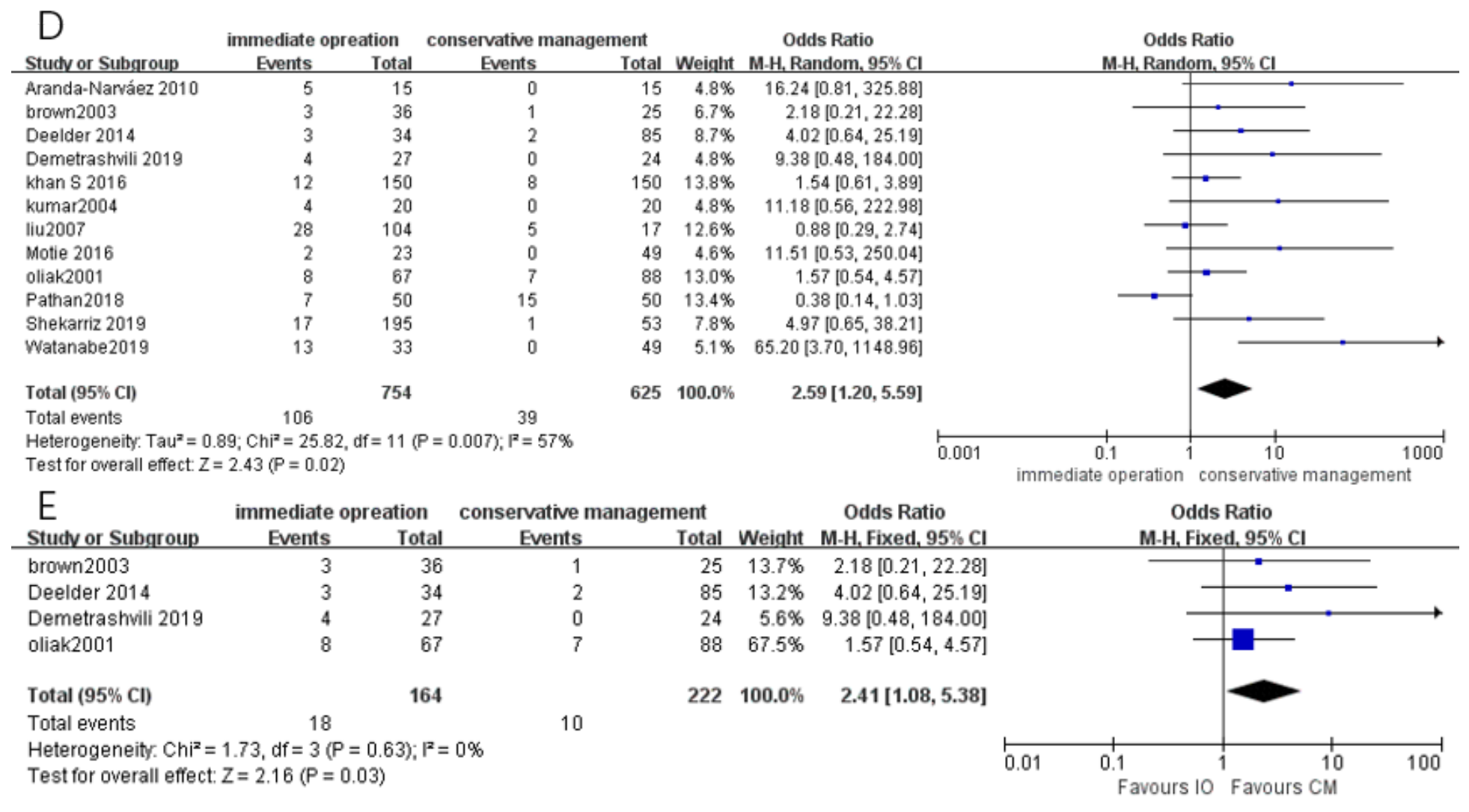

Figure 4

D. Wound infections. E. Wound infection in percutaneous drainage patients. 


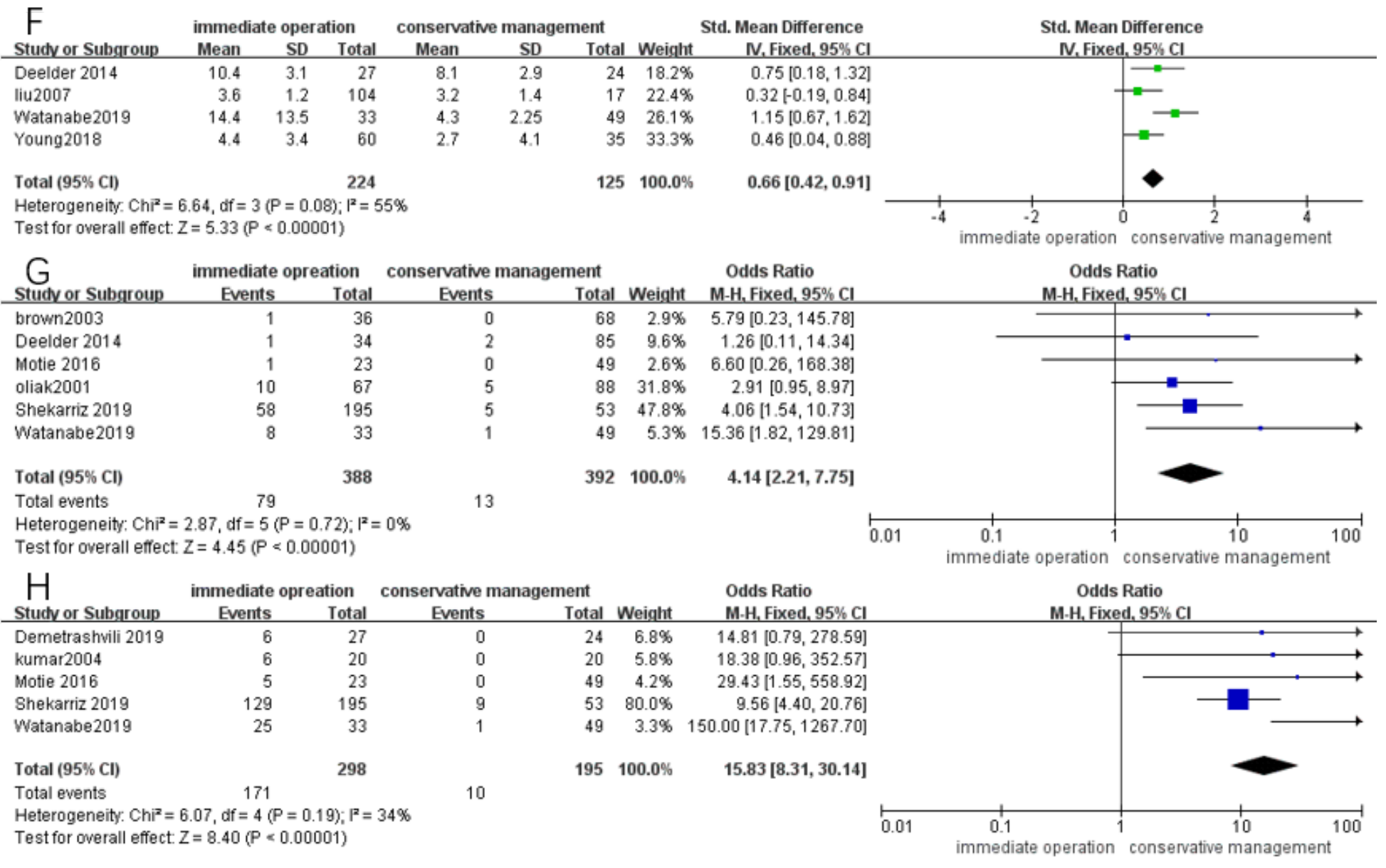

\section{Figure 5}

F. Post-operation stay, G. Intestinal obstruction. H. Post-operative complications

\section{Supplementary Files}

This is a list of supplementary files associated with this preprint. Click to download.

- terms.MYI

- terms.MYD

- terms.frm

- reftype.frm

- refsext.MYI

- refsext.MYD

- refsext.frm

- refs.MYI

- refs.MYD

- refs.frm 
- pdfindex.MYI

- pdfindex.frm

- misc.MYI

- misc.MYD

- misc.frm

- jterms.MYI

- jterms.MYD

- jterms.frm

- db.opt

- csort.MYI

- csort.MYD

- csort.frm

- studylist.txt 